\title{
Adaptação curricular no Ensino de Ciências: reflexões de professores de escolas inclusivas
}

\author{
Curriculum adaptation in Science Education: considerations of teachers in \\ inclusive schools
}

\section{Adaptación curricular en educación científica: consideraciones de los docentes en escuelas inclusivas}

\author{
Mônica Silveira Bereta \\ Mestra pela Universidade Luterana do Brasil, Canoas, RS, Brasil \\ E-mail: monicabereta@hotmail.com ORCID: https://orcid.org/0000-0002-6055-9362 \\ Marlise Geller \\ Professora doutora da Universidade Luterana do Brasil, Canoas, RS, Brasil \\ E-mail: marlise.geller@gmail.com ORCID: https://orcid.org/0000-0002-9640-2666
}

Recebido em 23 de novembro de 2020

Aprovado em 02 de março de 2021

Publicado em 23 de março de 2021

\section{RESUMO}

Nos últimos anos tem sido observado um crescente aumento no número de matrículas de estudantes com deficiência, principalmente nas escolas públicas regulares de todo o Brasil. Esses alunos têm seus direitos assegurados por lei, devendo ter acesso à escola com uma educação de qualidade juntamente com seus colegas. Sustentada neste entendimento, o presente artigo é um recorte da dissertação de mestrado desenvolvida ao Programa de Pós-Graduação em Ensino de Ciências e Matemática da Universidade Luterana do Brasil, que objetivou refletir sobre a adaptação curricular no ensino de Ciências, na perspectiva da educação inclusiva. A pesquisa, de natureza qualitativa, teve como proposta um curso a professores que ensinam Ciências no município de Gravataí-RS e os dados, que emergiram da interação dos participantes ao longo do curso, foram analisados inspirados nas premissas da análise descritiva interpretativa. A pesquisa aponta indícios de que dentro da proposta de uma escola inclusiva, a adaptação curricular é uma estratégia importante para que os estudantes tenham acesso aos conhecimentos científicos. Entretanto, os professores necessitam aprofundar discussões sobre a temática para realizar ajustes nos conteúdos do currículo.

Palavras-chave: Adaptação curricular; Ensino de Ciências e Inclusão; Formação de Professores.

\section{ABSTRACT}

Over the last few years, the number of disabled students enrollments, mainly in regular public schools across Brazil, has been increasingly growing. These students' rights are guaranteed by law, and thus, they must have access to school and receive a quality education alongside their classmates. Based on this understanding, the present paper is an 
excerpt from a Master's dissertation presented to the Postgraduate Program in Teaching of Science and Mathematics at ULBRA, which aimed to reflect on curricular adaptation in Science Teaching, within the perspective of Inclusive Education. The qualitative research proposed a course for Science teachers from the municipality of Gravataí in Southern Brazil, and the data collected from the participants' interactions throughout the course was analyzed, inspired by the premises of the descriptive interpretative analysis. The research indicates that within the proposal of an inclusive school, curricular adaptation is an important strategy to ensure student access to scientific knowledge. However, teachers need to deepen discussions on the subject to make curriculum adjustments.

Keywords: Curriculum adaptation; Science Teaching and Inclusion; Teacher Education.

\section{RESUMEN}

En los últimos años, ha habido un aumento creciente en el número de matrículas de estudiantes con discapacidades, principalmente en escuelas públicas regulares en todo Brasil. Estos estudiantes tienen sus derechos garantizados por la ley y deben tener acceso a la escuela y recibir una educación de calidad junto con sus colegas. En base a esta comprensión, el presente estudio es un extracto de la disertación de maestría presentada al Programa de Posgrado en Docencia en Ciencias y Matemáticas de la ULBRA, que tuvo como objetivo reflexionar sobre la adaptación curricular en la enseñanza de las Ciencias, desde la perspectiva de la educación inclusiva. La investigación cualitativa propuso un curso para docentes que enseñan ciencias en la ciudad de Gravataí-RS y los datos que surgieron de la interacción de los participantes a lo largo del curso, fueron analizados inspirados por las premisas del análisis descriptivo interpretativo. La investigación apunta a indicaciones de que dentro de la propuesta de una escuela inclusiva, la adaptación curricular es una estrategia importante para que los estudiantes tengan acceso al conocimiento científico. Sin embargo, los maestros aún necesitan discusiones y reflexiones para hacer ajustes al plan de estudios.

Palabras clave: Adaptación curricular; Enseñanza e inclusión de las ciencias; Formación de profesores.

\section{Introdução}

No Brasil, a temática da inclusão escolar tem ocupado um espaço cada vez maior nas políticas públicas, o que vem garantindo cada vez mais, o acesso de crianças e adolescentes com deficiências intelectual, sensoriais e motoras, transtornos do espectro autista, além de alunos com superdotação/altas habilidades nas escolas regulares de ensino de todo o país, com o suporte do Atendimento Educacional Especializado - AEE, normalmente no contra turno da aula, em todos os níveis de ensino (BRASIL, 2018). Entretanto, a educação inclusiva não se refere apenas a matricular o aluno na escola, tratase de acolher e respeitar as diferenças individuais de cada um, proporcionando acessibilidade e garantindo a aprendizagem de acordo com suas peculiaridades. 
A Lei de Diretrizes e Bases da Educação no artigo 59 estabelece que:

[...] Os sistemas de ensino assegurarão aos educandos com deficiência, transtornos globais do desenvolvimento e altas habilidades ou superdotação: currículos, métodos, técnicas, recursos educativos e organização específica para atender as suas necessidades (BRASIL, 2017).

Portanto, compete à escola se reorganizar e promover as adaptações necessárias, como, aquisição de materiais e equipamentos, adaptações estruturais da escola, nos conteúdos, objetivos, atividades e critérios de avaliação, ajustando o currículo oficial da escola para atender às diferenças individuais do estudante.

Dentro da proposta de escola inclusiva, e relacionando com o ensino de Ciências, a adaptação curricular pode ser compreendida como uma estratégia extremamente importante, pois auxilia o trabalho docente, garantindo que os alunos tenham acesso aos conhecimentos científicos referentes ao ano escolar que frequentam. Para isso, os professores que ensinam Ciências precisam ser orientados para realizar ajustes no currículo, a fim de facilitar o processo de aprendizagem dos estudantes. Essas orientações podem ser recebidas na formação inicial ou por meio de capacitações específicas, alternativa essa sugerida nesta pesquisa. Neste contexto, este artigo relata um recorte de uma pesquisa de mestrado que objetivou investigar o processo de adaptação curricular, na perspectiva da educação inclusiva, realizado por docentes que ensinam Ciências em escolas regulares por meio de uma pesquisa qualitativa (BERETA, 2019).

\section{A formação docente e a construção de adaptações curriculares}

Os professores que ensinam Ciências, bem como os professores das demais áreas, observaram nos últimos anos, mudanças significativas no cenário da educação brasileira, principalmente com o contexto da educação inclusiva, que contempla a exigência de diversas reformulações, entre elas, a necessidade de se discutir também a formação do professor neste processo.

$O$ atendimento aos estudantes com deficiência exige um trabalho diferenciado, flexível, já que as práticas educativas tradicionais podem não atender suas necessidades, precisando muitas vezes haver uma adaptação curricular para que o aluno consiga compreender melhor os conceitos abordados, buscando acompanhar os colegas, mas sendo observado e respeitado seu tempo de aprendizagem. Capellini (2018) defende que as adaptações curriculares, podem ser entendidas como uma estratégia didáticopedagógica que considera as diferenças acadêmicas e os ritmos de aprendizagem dos 
http://dx.doi.org/10.5902/1984686X63190

estudantes, permitindo contemplar a diversidade em questão, oferecendo alternativas educativas aos estudantes que apresentam dificuldades de se apropriar dos conteúdos curriculares para ano que estão frequentando. No entanto, o estudo de Adams (2018) revela que grande parte dos professores não sabe como realizar as adaptações curriculares e elaborar metodologias para atender os alunos com deficiência.

Para Adams (2018), a causa do despreparo dos professores é devido à desconsideração do público-alvo da educação especial nas matrizes curriculares dos cursos de formação de professores. Sousa (2017) defende que, em se tratando de educação inclusiva, a formação do professor é um fator crucial. Sendo assim, os cursos de licenciatura deveriam incluir maior número de disciplinas e atividades de educação especial em seus currículos, pois, é necessário que o professor se perceba preparado e seguro para trabalhar com esse contexto. Na mesma linha de pensamento, Pimentel (2012) considera que a ausência de conhecimento a respeito das deficiências, das potencialidades dos estudantes e adequação do currículo, podem ser fatores determinantes para o surgimento de barreiras, como a insegurança dos professores em relação à inclusão.

Garnica et al. (2016) ressaltam que a legislação brasileira traz orientações sobre a temática da educação inclusiva para os cursos de formação inicial de professores, contudo estudos como os de Fernandes e Rosa (2013), Silva e Salgado (2017) e Adams (2018) demonstram que ainda há muitas dificuldades em colocá-las em prática. Os cursos de licenciatura que preparam professores para o ensino de Ciências, nos casos em que apresentam uma disciplina com conteúdo relacionado à educação especial, há pouca margem para aprofundamento, em razão da carga horária limitada. Outra observação é que há uma predominância da disciplina de Libras, em relação aos demais temas relacionados à proposta de educação inclusiva, suprindo apenas a necessidade dos cursos se enquadrarem nas exigências da legislação.

Corroborando com esse viés,

[...] as discussões sobre educação especial não são frequentes como deveriam ser nos cursos de formação inicial e mesmo quando há esta não é suficiente, pois está pautada na legislação, não se discute os tipos de deficiência e as suas especificidades o que seria fundamental para preparar os futuros professores para lidarem com as especificidades dos alunos público alvo da educação especial, pois e conhecendo as especificidades do aluno com deficiência que o professor se torna capaz de elaborar aulas que levem em consideração as suas potencialidades (ADAMS, 2018, p. 93).

De acordo com o exposto, percebe-se que a formação inicial ainda deve ser repensada, de forma crítica, para contemplar o professor que ensina Ciências para atuar 
http://dx.doi.org/10.5902/1984686X63190

com a diversidade. O docente aprende e se profissionaliza continuamente com a dinâmica escolar, entretanto o trabalho em uma escola inclusiva exige base teórica e metodológica para que o professor, diante dos casos de inclusão, possa buscar novas estratégias de ensinar. De acordo com Pimentel (2012), para que o professor consiga assegurar o atendimento de todos em sua sala de aula, será necessário refletir sobre o currículo proposto, os conteúdos existentes e objetivos definidos. A partir deste aspecto, há de se considerar a existência de diferentes caminhos para a aprendizagem e buscar recursos que a favoreçam, ainda que em tempos diferentes.

\section{Metodologia}

Esse artigo recorte de uma pesquisa de Mestrado, descreve um curso para docentes, com questões abertas que permitiam a expressão dos indivíduos sobre suas experiências. A pesquisa foi desenvolvida nos anos de 2018 e 2019 no Programa de Pós-Graduação em Ensino de Ciências e Matemática (PPGECIM-ULBRA) e aprovada pelo Comitê de Ética sob protocolo número CAAE: 89370618.9.0000.5349.

Participaram do curso, 10 professoras do município de Gravataí que atuam com o ensino de Ciências no Ensino Fundamental, com formação inicial nos cursos de licenciatura em Ciências Biológicas (4 participantes), Matemática (1 participante) e Pedagogia (5 participantes). As participantes da pesquisa receberam códigos para identificação, com base em sua graduação, preservando seu anonimato. A figura 1 explicita suas informações, perante os códigos atribuídos a elas. Os códigos foram definidos por uma letra maiúscula e um numeral, identificados pelas letras C para Ciências, M para Matemática e P para Pedagogia, seguidos de numeral, o que diferencia as participantes.

Figura 1 - Códigos atribuídos as participantes da pesquisa

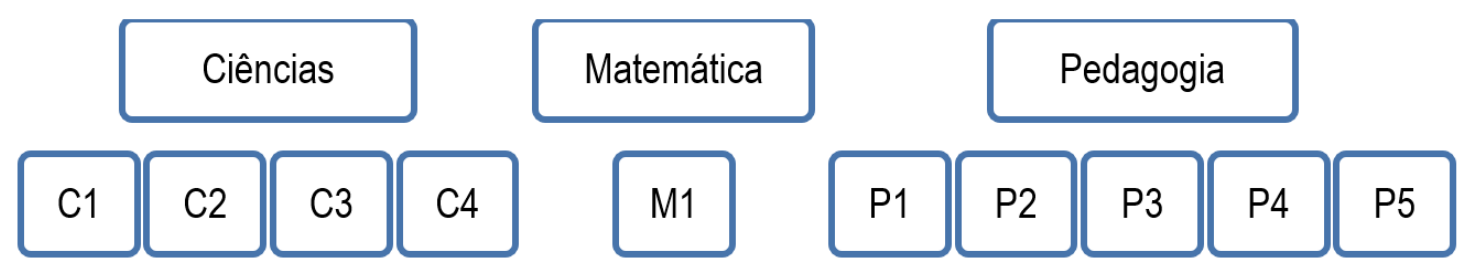

Fonte: (BERETA, 2019, p. 52).

O curso de formação continuada intitulado "Adaptação Curricular e o ensino de Ciências", com carga horária de 30 horas, foi ofertado no ambiente virtual de aprendizagem Moodle. Foram propostas seis aulas para as quais foram disponibilizados documentos, 
http://dx.doi.org/10.5902/1984686X63190

materiais de aula, vídeos, leituras complementares e fóruns de discussão, referentes às pautas propostas pelas pesquisadoras. Os dados originados com o curso foram posteriormente analisados e selecionados, buscando-se agrupamentos de ideias, inspirando-se na análise descritiva interpretativa proposta por Rosenthal (2014).

\section{Analisando os resultados}

Após a análise das informações, contidas nas respostas dos fóruns do curso, emergiram dois aspectos que se destacaram nas participações das docentes: Inquietações dos professores sobre adaptação curricular e Potencialidades da adaptação curricular para o ensino de Ciências. Além da análise desses aspectos, subsidiam a discussão, a proposta de planos elaborados pelas docentes ao final do curso. Com esses planos, não se pretende limitar o conceito de adaptação curricular, mas inferir sobre os mesmos, como alternativas para aprofundar reflexões sobre a construção de currículos adaptados, mais flexíveis às necessidades de cada estudante na perspectiva da educação inclusiva.

\section{Inquietações dos professores sobre adaptação curricular}

Ao iniciar o curso foi proposto um primeiro fórum onde as docentes, participantes da pesquisa, pudessem se apresentar e contar um pouco de sua experiência profissional. De acordo com os dados, todas já tiveram em sua trajetória profissional alguma experiência com estudantes da educação especial em suas turmas, fato que se relaciona com o crescente aumento de matrículas de alunos público-alvo da educação especial. O Censo Escolar (BRASIL, 2018) registrou 1,2 milhões de matrículas de alunos público alvo da educação especial em 2018, um aumento de 33,2\% em relação a 2014 , sendo $70,9 \%$ concentradas no ensino fundamental.

De acordo com os relatos das cursistas, mesmo atuando como docentes há bastante tempo (8 professoras, com mais de 10 anos no exercício da docência), as professoras ainda se sentem despreparados para trabalhar com estudantes com deficiência, seja intelectual, sensorial ou motora, transtornos do espectro autista, além de superdotação/altas habilidades, devido a singularidades de cada caso. O que pode ser exemplificado com o relato de P3: 
http://dx.doi.org/10.5902/1984686X63190

Mineto (2008) salienta que as incertezas quanto ao processo de inclusão, não são exclusividade dos professores, mas de todas as pessoas diante da diversidade. Quando o professor recebe um estudante com deficiência, pode se sentir confuso, o que é completamente compreensível, o novo gera sensação de insegurança e instabilidade, pois exige reorganização e mudança. Essa autora ressalta, ainda, que o professor precisa identificar suas dificuldades, sejam elas teóricas ou de práticas, e buscar soluções de aprimorar suas competências, pois quanto mais se conhece sobre determinado fato ou assunto, mais se sente seguro diante dele.

Na mesma linha de pensamento, Adams (2018), Garnica et al (2016), Pimentel (2012) e Sousa (2017) revelam que os professores, de modo geral, consideram-se despreparados para trabalhar com estudantes com deficiência devido às lacunas deixadas na formação inicial. Sousa (2017) realizou um estudo sobre a formação docente e seus resultados mostraram que os cursos de licenciatura, em quase sua totalidade, não contemplam disciplinas de educação especial ou educação inclusiva. O que resulta no surgimento de barreiras no momento de trabalhar com alunos com deficiência. Tal fato pode ser ilustrado na fala da participante P2: "Sou professora há 20 anos. Já tive vários alunos de inclusão e assim como os outros alunos, estes também têm suas peculiaridades, mas para essas, eu não fui previamente preparada" (P2).

Com relação ao processo de construção das adaptações curriculares, as participantes destacam que uma das grandes inquietações é o fato de não terem recebido formação adequada que as preparassem para construir currículos adaptados que atendam às necessidades de um público com tantas peculiaridades. De acordo com P2: "Não recebi formação para trabalhar com a inclusão e as poucas formações não se aprofundam na adaptação curricular" (P2).

A professora P3 destaca a importância de formações específicas sobre adaptação curricular, pois relata que:

[...] já realizei várias adaptações curriculares e sempre senti muita dificuldade ao fazê-las, pois nunca houve um preparo para isso, sinto muita falta dessa atenção ao professor, ter formações voltadas para isso para que possamos compreender melhor esse processo de adaptação (P3).

Pimentel (2012) acredita que a ausência de conhecimento por parte do professor, sobre as peculiaridades das deficiências, gera dificuldade de reconhecer as potencialidades dos estudantes, levando as docentes a manter uma organização curricular rígida e homogênea, o que não atende as necessidades desses alunos. Bereta 
http://dx.doi.org/10.5902/1984686X63190

e Geller (2018) também observam que os professores se sentem despreparados e com pouco conhecimento para reconhecer as habilidades do aluno e preparar materiais, encontrando grandes dificuldades em adaptar alguns conteúdos de Ciências às necessidades e ao ritmo dos estudantes.

A falta de conhecimento é recorrente na fala das participantes durante o curso e, pode ser apontada como a causa para suas principais inquietações. Para P2, sua maior dificuldade está relacionada ao desconhecimento das limitações dos alunos, resultando em dificuldade para selecionar as estratégias adequadas para abordar determinados assuntos:

[...] Já fiz várias adequações curriculares e minha maior dificuldade é não ter o conhecimento mais aprofundado das reais limitações do aluno em questão; o que fará realmente diferença e até onde poderei ir? Como encontrar estratégias que contemplem determinados assuntos e que sejam adequados às dificuldades/limitações desse aluno? (P2).

A participante M1 destaca que sua falta de conhecimento resulta em dificuldade para estabelecer os objetivos frente às limitações: "Percebo que as maiores dificuldades são em definir os objetivos específicos para o aluno" (M1).

Sabe-se que o professor tem um papel fundamental no êxito de seus alunos, mas é errôneo acreditar que somente o professor está despreparado. Capellini (2018) afirma que as escolas precisam rever suas concepções de cultura, funcionamento, organização, propostas pedagógicas de modo que atendam às necessidades educativas de todos. Os relatos das professoras P1 e P5 demonstram que as escolas, como um espaço de construção de conhecimento, também precisam se preparar e reconhecer a importância das adaptações curriculares.

[...] atualmente tenho três alunos que precisei realizar adaptações curriculares, está sendo um grande desafio, pois não tenho conhecimento e experiência na área e a estrutura da escola também não possui este preparo (P1).

[...] a maior dificuldade em construir as adaptações são os recursos, que muitas escolas não disponibilizam, e não reconhecem a importância de ter recursos diferentes em sala de aula (P5).

Respostas à diversidade, implicam em introduzir mudanças nas práticas educacionais tradicionais, fato que pode causar temores aos profissionais e dirigentes das escolas. Segundo Blanco (2004), tais temores podem ser amenizados se a tomada de decisão for realizada em conjunto, envolvendo a comunidade escolar. Ainda de acordo com a autora, o momento de tomada de decisões a respeito das adaptações curriculares, 
http://dx.doi.org/10.5902/1984686X63190

deve ser um projeto da escola e não dos professores, de forma isolada. Nesse contexto, entende-se que, no momento de construção das adaptações curriculares, devem estar presentes todos os envolvidos na aprendizagem do aluno.

De acordo com as participantes da pesquisa, percebe-se que as professoras compactuam com Blanco (2014), em relação à importância da participação dos demais membros da equipe diretiva/pedagógica na escolha das adaptações curriculares.

[...] acredito que não cabe apenas ao professor essa responsabilidade de elaborar seguir o currículo adaptado, esse deve ser um compromisso e responsabilidade de toda a equipe pedagógica da escola. Na minha escola é elaborado em parceria com a sala de recursos, orientadora, supervisora e professora titular (C4).

[...] É no momento da interação do professor da sala de aula com o AEE e a supervisão pedagógica que se consegue abordar de vários ângulos a elaboração da adaptação escolar, discutindo sobre as melhores estratégias, quais objetivos, como avaliar que se ampliam as condições para o processo de aprendizagem do aluno. E com esse apoio o professor acaba tendo mais segurança para elaborar atividades condizentes para os alunos (M1).

Minetto (2008) defende que a escola, ao receber um aluno, deve organizar uma rede de apoio ao professor, promovendo reuniões incluindo os profissionais da escola, a família e profissionais que atendem o aluno fora da escola para que se possa estabelecer estratégias conjuntas e dividir responsabilidades. O professor precisa ter essa rede que o acompanhe, incentivando-o e apoiando-o na busca de alternativas e práticas metodológicas adequadas para atender as suas demandas de sala de aula.

Para Silva (2015), alunos com deficiência exigem do professor um trabalho diferenciado com ações e estratégias planejadas de acordo com os objetivos que se pretende alcançar. Nesse sentido, é necessário que o professor tenha auxílio dos profissionais da escola que podem fornecer informações sobre os estudantes e suas deficiências. Portanto, a autora sugere que o professor regente e o professor que atende o aluno no Atendimento Educacional Especializado, formem uma parceria para elaboração de ações e estratégias que serão propostas para o aluno. Na visão de Zaboroski (2017, p.124), por meio da parceria, "os professores discutiriam e desenvolveriam as adaptações curriculares necessárias aos estudantes visando à aprendizagem e a continuidade em seu processo de escolarização".

Com base nas respostas das participantes observa-se que as mesmas reconhecem a importância da parceria com a professora do AEE, sentindo-se mais amparados na escolha das adaptações adequadas. 
http://dx.doi.org/10.5902/1984686X63190

[...] é a primeira vez que consigo ter o auxílio do AEE. No início do trimestre sentamos juntos e construímos o currículo para cada aluno que é atendido na sala de recursos. Esse currículo foi feito individualmente, em cima das potencialidades de cada um e por disciplina ou por área de conhecimento. Nesse momento trocamos ideias e vemos as possibilidades de construção de materiais que são necessários de acordo com as necessidades e dificuldades de cada um (se não escreve, é feito um material com figuras e assim por diante) (C3).

[...] a adaptação curricular tem como base os conteúdos de Ciências a serem trabalhados na série em questão. Eu particularmente, me sinto mais segura construindo a adaptação curricular junto com a professora do AEE, pois a priori é quem possui maior conhecimento das limitações do aluno em questão. Agradeço muito a atuação e apoio da profissional do AEE, porque sem esse apoio e parceria, nada seria possível (P2).

Segundo Lippe e Camargo (2009), para que a inclusão realmente aconteça é fundamental a presença de um professor especialista, para orientar e ajudar tanto os alunos, quanto os professores. Frente aos relatos, percebe-se que o professor do AEE é uma figura importante para os professores participantes, pois, na maioria dos casos, é do profissional do AEE que vem o auxílio na escolha das adaptações curriculares. Mas os professores de AEE só são capazes de orientar professores no processo de ensinar e aprender em uma perspectiva inclusiva, uma vez em seus cursos recebem formações específicas sobre as deficiências. Tais informações também seriam de grande relevância aos professores que trabalham com o ensino de Ciências, pois tornaria, tanto a adaptação do currículo quanto o planejamento de aulas, processos mais inclusivos, voltados para a busca da aprendizagem, de acordo com as peculiaridades de cada estudante.

De acordo com os dados da pesquisa, pode-se perceber que, se tratando das adaptações curriculares para estudantes com deficiência, alguns fatores como sensação de insegurança e despreparo, falta de conhecimento e formação adequada, necessidade de mudanças na estrutura e na filosofia da escola e ausência de apoio e participação dos profissionais da escola, geram inquietações nas professoras participantes do curso.

\section{Potencialidades da adaptação curricular para o ensino de Ciências}

O segundo aspecto abordado relaciona-se as potencialidades da adaptação curricular para o ensino de Ciências, destacando as adaptações curriculares mais frequentes utilizadas pelas professoras.

Para garantir que todos os estudantes possam ter acesso aos conhecimentos científicos, as professoras participantes da pesquisa utilizam das adaptações curriculares. As docentes acreditam que as adaptações no currículo podem contribuir de forma 
http://dx.doi.org/10.5902/1984686X63190

significativa para a compreensão dos conhecimentos científicos, adequando o conteúdo às possibilidades e potencialidades do estudante. O relato de P3 expressa a ideia do grupo:

[...] O ensino de Ciências para os alunos de inclusão será mais significativo com adaptação curricular, pois a compreensão dos conhecimentos por parte do aluno será dentro das limitações dele, com isso o docente conseguirá avanços na aprendizagem do aluno (P3).

Corroborando com essa premissa, Guadagnini e Duarte (2015) trazem que a literatura tem apontado o papel relevante das adaptações curriculares, sendo que a adaptação de recursos e estratégias pedagógicas consistentes podem favorecer a aprendizagem dos conteúdos escolares pelos estudantes com deficiência. A professora P1 expressa opinião em consonância com essas autoras, quando relata: "Acredito que a adaptação curricular pode ajudar no ensino de Ciências proporcionando melhor compreensão do conteúdo".

Dalonso (2017) destaca que a adaptação curricular é um recurso que proporciona avanços sucessivos dos estudantes da educação especial. Portanto, os professores devem estar atentos aos ajustes necessários no currículo, adequando, flexibilizando ou modificando as propostas, como alternativa de garantir acesso aos conhecimentos, preservando seu direito à educação e ao acesso as informações. A docente M1 destaca que a adaptação curricular, além de possibilitar o acesso aos conteúdos científicos, pode, ainda, servir de referência para modificações maiores que se refletirão no desenvolvimento dos estudantes.

[...] A adaptação curricular pode contribuir e muito para o ensino de Ciências. Partindo de um pressuposto, seguem-se diferentes formas de auxiliar os alunos na aprendizagem escolar e que acaba também levando para a vida. As adaptações curriculares são importantíssimas até porque servem como um dos referenciais para possíveis ajustes para auxiliar no desenvolvimento global do aluno (M1).

Os dados obtidos revelam que as adaptações curriculares são benéficas também para os professores que ensinam Ciências, pois servem como pontos norteadores para o desenvolvimento do trabalho pedagógico. As falas de P5 e C2 ilustram que:

[...] a adaptação curricular coloca o conteúdo o mais próximo possível do aluno, o que facilita o trabalho do professor e a aprendizagem do aluno mediante aos recursos que lhes são propostos nesta adaptação (P5).

[...] Nós precisamos de ferramentas onde possamos planejar e traçar objetivos com intuito de fazer com que o aluno de inclusão possa construir seu conhecimento e, nesse aspecto, a adaptação curricular se faz imprescindível para nosso trabalho (C2).

Silva (2015) pondera, em seus estudos, que a adequação curricular é um recurso que fornece subsídios para a prática diária do professor, estabelecendo estratégias para 
atender as especificidades do aluno, fornecendo possibilidades de atingir os objetivos propostos para sua aprendizagem, participação e desenvolvimento. Nessa pesquisa, pode-se inferir que, para as professoras participantes, o envolvimento nesse trabalho, além de auxiliar na eliminação das barreiras de aprendizagem de seu aluno, também serve de incentivo para a busca de conhecimentos sobre a diversidade.

Para Lopes (2017), diante da diversidade presente nas salas de aulas regulares, o professor pode adotar um ensino com práticas pedagógicas heterogêneas. Neste sentido, a adaptação curricular é uma ferramenta que contribui para que os professores consigam conduzir seu trabalho e promover a democratização dos saberes acumulados pela humanidade.

A análise dos registros dos participantes, nessa pesquisa, aponta que o contato com a inclusão escolar despertou nas professoras a necessidade de buscar conhecimentos para adequar suas aulas às diferenças, corroborando com essa ideia, salienta-se a fala de M1 como exemplo: "Cada ser é único com habilidades e conhecimentos diferentes. Partindo desse pressuposto, porque todos deveriam aprender tudo da mesma forma? Ainda temos muito a aprender...".

Bezerra e Oliveira (2016) salientam que a heterogeneidade influencia na reorganização curricular de toda a sala de aula, gerando melhorias nas práticas educativas para todos. Tal fato aparece nas respostas das professoras, como exemplo, destaca-se a fala da professora C3: "A adaptação curricular contribui muito, não só para o aluno de inclusão, mas também para os demais alunos".

A Lei Brasileira de Inclusão da Pessoa com Deficiência (BRASIL, 2015) defende que uma escola realmente inclusiva é aquela que reconhece que todos são diferentes, e procura, por meio de alternativas pedagógicas diferenciadas, garantir que os alunos construam seus conhecimentos e tornem-se cidadãos. Para isso, segundo Silva (2015), cabe ao professor, por sua vez, utilizar uma ferramenta pedagógica importante, as adaptações curriculares.

Os dados, nessa pesquisa, revelam apenas algumas das potencialidades da adaptação curricular no ensino de Ciências, como por exemplo: uma melhor compreensão dos conteúdos e conhecimentos científicos, o que reflete do desenvolvimento global do estudante com deficiência; norteia o trabalho do professor e incentiva a busca de conhecimento, resultando em avanços no trabalho com todos os estudantes. 
http://dx.doi.org/10.5902/1984686X63190

\section{Propostas de adaptações curriculares para o ensino de Ciências}

Ao se propor investigar como os professores realizam a adaptação curricular, a partir de materiais e estratégias pedagógicas, foram elaboradas, pelas professoras participantes da pesquisa, propostas de planos adaptados como alternativas de viabilizar o ensino de Ciências às especificidades dos estudantes. Essas propostas emergem das reflexões ao longo do curso e subsidiam a prática docente.

Foram escolhidos quatro planos para análise, cuja seleção considerou diferentes deficiências, presentes no cotidiano escolar das professoras. Para cada plano foi elaborada uma síntese das principais adaptações realizadas pelas professoras, como pode ser visto a partir da análise do plano 1, indicado na figura 2.

Figura 2 - Plano 1: elaborado pela participante C2 e síntese de sua adaptação

\begin{tabular}{|l|l|}
\hline Informações do aluno: & $\begin{array}{l}\text { Aluna de 14 anos com Deficiência Visual - } 8^{\circ} \text { ano do Ensino Fundamental. } \\
\text { A aluna é interessada pelas aulas de Ciências, sente curiosidade e questiona } \\
\text { quando apresenta dúvidas, acompanha o desenvolvimento cognitivo para sua } \\
\text { idade/série, comunica-se bem, apresenta vocabulário complexo e demonstra } \\
\text { curiosidade pelas descobertas cientificas. Necessita de material tátil adaptado } \\
\text { para compreensão dos conteúdos da disciplina, é capaz de elaborar conceitos } \\
\text { de mundo a partir de explicação teórica. }\end{array}$ \\
\hline $\begin{array}{l}\text { Conteúdo: Tipos } \\
\text { Celulares }\end{array}$ & $\begin{array}{l}\text { A aula inicia com explicação teórica do conteúdo através da escrita (aluna } \\
\text { recebeu texto em Braille) e depois comunicação oral destacando os tipos } \\
\text { celulares animal, vegetal e bacteriano. Após, foram apresentados protótipos } \\
\text { táteis em relevo (3D) para representar as organelas, cada célula apresentava } \\
\text { a organela e sua respectiva legenda com a descrição Braille/tinta ampliada. } \\
\text { Todos os alunos puderam diferenciar os tipos celulares de maneira tátil ou } \\
\text { visual, além de destacarem as organelas em comum entre as células. }\end{array}$ \\
\hline Avaliação: & $\begin{array}{l}\text { A aluna será avaliada a partir de prova (em Braille) trimestral com questões } \\
\text { dissertativas (máquina Braille). Além disso, também será estimulada a expor } \\
\text { sua percepção do conteúdo (de forma oral) para o grupo usando os } \\
\text { protótipos celulares como recurso. }\end{array}$ \\
\hline
\end{tabular}

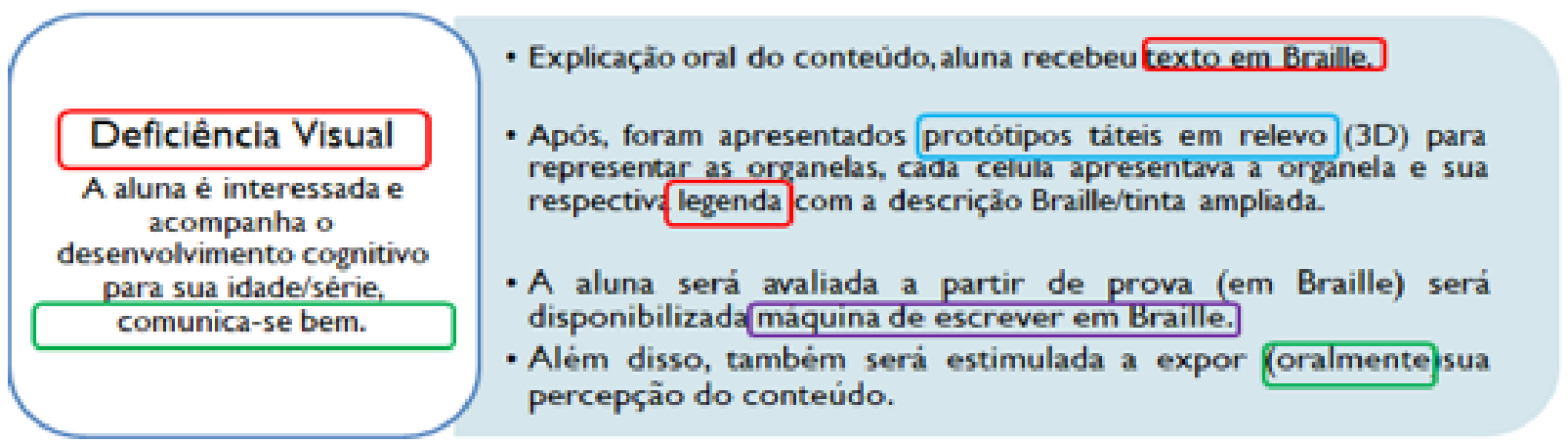

Fonte: (BERETA, 2019, p. 75). 
http://dx.doi.org/10.5902/1984686X63190

No exemplo da figura 2, pode-se destacar a adaptação no uso de material em Braille, como forma de registro teórico, por se adequar a necessidade da aluna, já que a mesma não enxerga as letras do quadro ou livro. Durante as explicações orais da professora, essa aluna teve acesso a materiais concretos para a exploração tátil, o que facilitou a sua compreensão do conteúdo.

A professora $\mathrm{C} 2$ reforça em um dos seus relatos que, para estudantes com deficiência visual (no caso específico, com visão residual), é fundamental fazer a associação do conteúdo com "[...] figuras e imagens com relevo, bem coloridas e chamativas, além de meios sonoros, visuais, áudio-descrição e modelagem com massinha de modelar".

Para Bereta e Geller (2018), a utilização de recursos auditivos, visuais, além de materiais que o estudante possa manusear, podem ser excelentes alternativas de aprendizagem a serem exploradas.

Os instrumentos de avaliação também foram adaptados, com uma prova confeccionada em Braille, com a disponibilização de máquina Braille para as respostas, além da exposição oral, explorando, assim, a facilidade que a estudante tem de se comunicar por meio da linguagem oral. A professora C2 acredita que a avaliação de forma oral, com relato do conteúdo, pode ser uma excelente alternativa para que o estudante com deficiência visual demonstre sua compreensão sobre o tema.

Corroborando com os dados aqui apresentados, Silva e Salgado (2017) destacam, em seus estudos com professores que ensinam Ciências para alunos com deficiência visual, que a utilização de material concreto, massinha de modelar, aulas práticas, escrita Braille, textura e utilização de avaliações e tarefas orais, como discussões e debates, são estratégias para proporcionar a construção de conhecimentos científicos aos estudantes.

É importante ressaltar que, em alguns casos, como por exemplo, de alunos com deficiência visual, determinadas adaptações curriculares exigem a aquisição de materiais e equipamentos específicos, como a máquina Braille. Entretanto, tais adaptações só serão possíveis se houver a compreensão e o apoio do sistema (equipe diretiva da escola, secretarias de educação e serviços de apoio à educação especial), disponibilizando recursos e compartilhando a decisão sobre o que pode ou não ser providenciado.

No plano de aula 2, conforme figura 3, a professora C2 adaptou sua metodologia, optando pela explicação do conteúdo feita de forma resumida e visual, utilizando figuras e textos objetivos no Power Point, adequado ao ritmo do estudante, que apresenta dificuldades em focar e realizar as atividades. 
http://dx.doi.org/10.5902/1984686X63190

Figura 3 - Plano 2: elaborado pela participante C2 e síntese de sua adaptação

\begin{tabular}{|c|c|}
\hline Informações do aluno: & $\begin{array}{l}\text { Aluno com Deficiência Intelectual leve e transtorno social - } 12 \text { anos - } 6^{\circ} \text { ano d } \\
\text { Ensino Fundamental. } \\
\text { caluno tem dificuldade em focar a sua atenção em sala, é impulsivo e se } \\
\text { caderno é desorganizado. Apesar disso gosta das aulas de Ciências. É ur } \\
\text { aluno comunicativo, expõe sua opinião com facilidade e gosta de faze } \\
\text { desenhos, possui boa motricidade fina; tem dificuldade na leitura e compreend } \\
\text { somente a letra bastão. }\end{array}$ \\
\hline $\begin{array}{l}\text { Plano de Aula } \\
\text { Conteúdo: Reino Animal }\end{array}$ & $\begin{array}{l}\text { Foram destacados, em uma apresentação Power Point, exemplos de sere } \\
\text { vivos e sua classificação. } \\
\text { Após, o aluno montou um portfólio com desenhos de exemplos de peixe } \\
\text { anfíbios, repteis, aves e mamíferos. Ali foram salientadas as principa } \\
\text { diferenças entre eles. Depois, o aluno recebeu uma caixa com animais e } \\
\text { miniatura, a partir daqueles elementos, ele deveria nomear a classificaçã } \\
\text { desses seres vivos. }\end{array}$ \\
\hline Avaliação: & $\begin{array}{l}\text { O estudante será avaliado a partir da produção de portfólio de seres vivo } \\
\text { sua dedicação em desenvolvê-lo. Além disso, também será estimulado a ex } \\
\text { sua percepção do conteúdo (oralmente) com o uso dos animais em miniatu }\end{array}$ \\
\hline $\begin{array}{l}\text { Aluno com Deficiência } \\
\text { Intelectual leve e } \\
\text { transtorno social }\end{array}$ & $\begin{array}{l}\text { - Power point com figuras de seres vivos e sua classificaçào. } \\
\text { - Após montagem de um porttolı com desenhos de exemplos de } \\
\text { peixes, anfibios, repteis, aves e mamiferos. Ali foram salientadas as }\end{array}$ \\
\hline $\begin{array}{l}\text { O aluno tem dificuldade em } \\
\text { focar sua atençio em aula. }\end{array}$ & $\begin{array}{l}\text { - O aluno recebeu uma caixa com animais em miniatura para nomear } \\
\text { e classificar. }\end{array}$ \\
\hline $\begin{array}{c}\text { É um aluno comunicativo e } \\
\text { gosta de fazer desenhos, } \\
\text { possui boa motricidade fina. }\end{array}$ & $\begin{array}{l}\text { - A avaliação será a partir da produção de portfólio, além disso, } \\
\text { também será estimulado a expor sua percepção do conteúdo } \\
\text { (oralmente) com o uso dos animais em miniatura. }\end{array}$ \\
\hline
\end{tabular}

Fonte: (BERETA, 2019, p.77)

A professora C2 relata que, ao longo do trabalho na educação inclusiva, passou a perceber que, além da modificação das atividades, havia a necessidade adaptação no tempo de realização das mesmas, adequando o tempo ao ritmo de cada aluno, indicando que "[...] consegui compreender a necessidade de ajuste do tempo para executar as tarefas".

As atividades de montagem do portfólio e a exposição oral, sobre as percepções do conteúdo, oportunizaram ao estudante o uso de alguns conhecimentos já desenvolvidos, como habilidades manuais e de comunicação.

A atividade da caixa de animais oportunizou a exploração de material concreto, com animais conhecidos pelo estudante, aproximando assim o conteúdo do seu dia a dia. Essa alternativa também foi citada pela professora $\mathrm{C} 1$, defendendo que "[...] a aprendizagem para 
http://dx.doi.org/10.5902/1984686X63190

esses alunos precisa contemplar os conhecimentos do cotidiano, com atividades relacionando os conteúdos com situações com as quais eles têm contato".

O instrumento de avaliação levou em consideração a dificuldade de concentração do estudante. A avaliação durante a realização de uma atividade específica, principalmente prática, pode ser adequada, por ser mais dinâmica, exigindo menos tempo de concentração, o que é interessante para este aluno. A professora M1 também defende a utilização da avaliação do desempenho dos estudantes durante as atividades, pois passa a considerar o momento que o aluno está mais envolvido com o conteúdo.

Figura 4 - Plano 3: elaborado pela participante P2 e síntese de sua adaptação

\begin{tabular}{|c|c|}
\hline $\begin{array}{l}\text { Informações do } \\
\text { aluno: }\end{array}$ & $\begin{array}{l}\text { Aluno com Autismo e baixa visão - } 14 \text { anos } 5^{\circ} \text { ano } \\
\text { Reconhece sílabas de palavras simples e conta até } 20 \text {. Gosta de contar histórias. } \\
\text { Necessita de auxilio de um profissional de apoio para a realização das atividades. } \\
\text { Dificuldade na motricidade fina. }\end{array}$ \\
\hline & $\begin{array}{l}\text { Organização da sala, alunos todos em dupla, o aluno em questão senta em dupla } \\
\text { com sua profissional de apoio. }\end{array}$ \\
\hline Plano de Aula & $\begin{array}{l}\text { Explicação oral do conteúdo, fazendo questionamentos, estimulando a } \\
\text { participação do aluno; }\end{array}$ \\
\hline $\begin{array}{l}\text { Conteúdo: Sistema } \\
\text { digestório }\end{array}$ & $\begin{array}{l}\text { O aluno recebe uma folha - ampliada- com as fases da digestão dos alimentos } \\
\text { (boca, esôfago, estômago, intestino e reto) e deve recortar (com tesoura adaptada) } \\
\text { coloca-las em ordem, colando e numerando (1-5) no seu caderno; }\end{array}$ \\
\hline & $\begin{array}{l}\text { A segunda atividade o aluno recebe uma folha com o nome das estruturas } \\
\text { (ampliada) e órgão trabalhados em aula sem as vogais, e deve completa-las de } \\
\text { forma correta. Exemplo: (B_C_;_NT_S). }\end{array}$ \\
\hline Avaliação: & $\begin{array}{l}\text { O estudante é avaliado de forma contínua, todos os dias ao longo da realização } \\
\text { das atividades propostas. }\end{array}$ \\
\hline
\end{tabular}

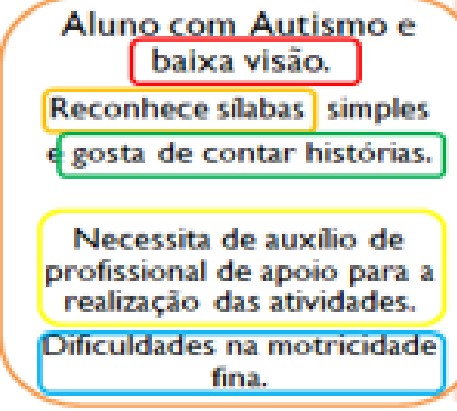

- Todos em dupla, o aluno em questão senta em dupla com sua profissional de apoio.

- Explicaçăo oral do conteúdo estimulando a participação do aluno;

- O aluno recebe uma atividade com as fases da digestão dos alimentos (ampliada) e deve recortar (tesoura adaptada) coloca-las em ordem, colando e numerando ( 1 -5) no seu caderno;

- O aluno recebe uma folha com o nome das estruturas (ampliada)]e órgajos trabalhados em aula sem as vogais, e deve completa-las de forma correta. Ex:(B_C_; D_NT_S).

- O estudante é avaliado de forma continua, todos os dias ao longo da realizaçăo das atividades propostas.

Fonte: (BERETA, 2019, p. 79).

No plano 3, apresentado na figura 4, a professora se preocupou inicialmente com a adaptação da sala de aula, organizando todos os alunos em duplas, assim o aluno se sentiria mais próximo aos colegas, já que o mesmo necessita de um profissional sentado ao seu lado 
http://dx.doi.org/10.5902/1984686X63190

Ihe auxiliando durante as atividades. A professora C3 destaca em suas contribuições seu hábito de oferecer trabalhos em duplas ou grupos, por acreditar que esse tipo de atividade promove a interação entre os colegas, destacando que "[...] trabalhos em grupo são muito bem aceitos por toda a turma".

A explicação oral, com interação entre os alunos e a professora, é uma alternativa relevante que pode ser explorada, já que o aluno ainda não está alfabetizado e tem baixa visão, sendo a oralidade sua principal forma de comunicação.

A primeira atividade, confeccionada com figuras em tamanho maior e com a disponibilização de uma tesoura adaptada, oportuniza ao estudante realizar a tarefa, já que suas necessidades visual e motora foram contempladas nessa atividade específica. Já a segunda atividade elaborada para completar o nome das estruturas estudadas no sistema digestório, permite ao aluno trabalhar com o mesmo contexto da turma, utilizando uma tarefa proposta de menor complexidade, adequando a atividade ao nível de alfabetização do aluno. A elaboração de atividades com menor complexidade, como alternativa de manter o estudante dentro do mesmo conteúdo trabalhado pela turma, também é uma estratégia utilizada pela professora M1, inferindo que "[...] para incluir os alunos (não alfabetizados) no contexto, trabalho com pinturas de desenhos e esquemas. Exercícios de forma oral'.

A professora C4 aposta na adaptação das atividades, indicando que: "Desenvolvo o conteúdo com trabalhos utilizando desenhos, recorte, colagem, massinha de modelar e argila".

A avaliação escolhida pela professora, de forma contínua, todos os dias ao longo da realização das tarefas propostas, permite juntar um número maior de informações sobre o estudante, além de seu processo de aprendizagem, seu comportamento e interesses ao longo das atividades. Para Hoffmann (2013), em uma avaliação na qual o educador observa continuamente seu aluno, ele acaba por reunir informações significativas sobre o seu próprio trabalho, possibilitando, assim, por meio de um agir/reflexivo, analisar e reconstruir sua prática pedagógica.

No plano de aula 4, descrito na figura 5, pode-se observar que a professora incentiva a participação da estudante na discussão proposta em aula, o que, provavelmente, possibilita a estudante sentir-se integrada à turma. Nascimento e Geller (2015) entendem que este aspecto é importante, pois o sentimento de fazer parte da turma pode influenciar de forma positiva no rendimento escolar do aluno com deficiência. O material teórico adaptado, na forma de um pequeno texto, permite a compreensão da estudante, já que a mesma tem bastante 
dificuldade em interpretar o que lê. A professora P3, ao falar das estratégias que utiliza para alunos com dificuldade de interpretação, descreve que utiliza "[...] material concreto, textos curtos e figuras".

Figura 5 - Plano 4: elaborado pela participante P3 e síntese de sua adaptação

\begin{tabular}{|c|c|}
\hline Informações do aluno: & $\begin{array}{l}\text { Aluna com Síndrome de Down - } 10 \text { anos - } 4^{\circ} \text { ano } \\
\text { Está alfabetizada, mas tem bastante dificuldade na produção de frases. No } \\
\text { raciocínio lógico demonstra dificuldade em memorizar os números e na } \\
\text { sequência lógica das atividades. Gosta de atividades lúdicas. Necessita de } \\
\text { auxílio para usar a tesoura, pois tem dificuldades na motricidade fina. }\end{array}$ \\
\hline Conteúdo: Germinação & $\begin{array}{l}\text { Nesta aula será proposta uma aula prática, será confeccionado um "Boneco } \\
\text { de alpiste" com toda a turma. } \\
\text { Primeiramente, será feita uma conversa sobre o assunto, procurando usar } \\
\text { palavras fáceis, para que a aluna entenda. A aluna será questionada e } \\
\text { incentivada a participar da discussão. Posteriormente a aluna recebe um } \\
\text { pequeno texto (com pontos principais) para ler e colar no caderno. A parte } \\
\text { prática será realizada no pátio da escola. Os alunos pegam os materiais } \\
\text { trazidos de casa (meia calça, tesoura e garrafa pet). Recebem sementes de } \\
\text { alpiste e iniciam a construção do boneco, conforme orientação da professora. } \\
\text { A aluna em questão recebe auxilio constante da agente de apoio, que a } \\
\text { auxilia no uso da tesoura e demais materiais. } \\
\text { Em um segundo momento, de volta em sala de aula, os alunos produzirão } \\
\text { um relatório da aula prática. A aluna em questão receberá frases do que foi } \\
\text { feito no pátio da escola e terá de organizá-las na ordem correta que } \\
\text { ocorreram, colar no caderno e numerar de forma crescente. }\end{array}$ \\
\hline Avaliação: & aluna será avaliada ao longo da atividade. \\
\hline
\end{tabular}

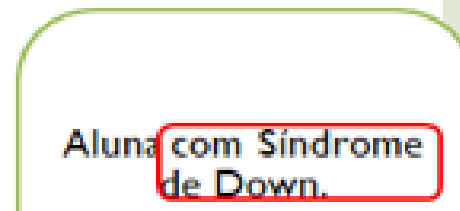

Está alfabetizada, mas tem dificuldade na produçăio de frases. Gosta de atividades lúdicas.
- Aula prática, será confeccionado um "Boneco de alpiste".

- Corversa sobre o assunto, procurando usar palavras fáceis, I mesma será questionada $e$ incentivada a participar da discussão. Posteriormente a aluna recebe um pequeno texto (com pontos principais).

- A prática da confecção do boneco será realizada no pátio da escola.

- A aluna questão recebe auxilio constante profissional de apoio Uso dettesoura adaptada.

- Produção de relatório. A aluna receberá frases do que foi feito no pátio da escola e terá de organiza-las na ordem correta que ocorreram.

- A aluna será avaliada ao longo da atividade.

Dentre as adaptações realizadas pela professora P3, a adaptação da linguagem científica merece destaque porque pode ser considerada uma grande barreira no ensino de Ciências. Benite, Benite e Vilela-Ribeiro (2015) ressaltam que o trabalho com estudantes com deficiência é bastante específico, uma vez que a transposição da linguagem científica para uma linguagem coloquial, mais simples e a adequação das atividades práticas, podem se 
http://dx.doi.org/10.5902/1984686X63190

tornar barreiras para a aprendizagem. Silva e Mesquita (2017) sugerem que os docentes dessa área passem por uma renovação didática que os possibilite fazer a mediação entre o conhecimento científico e o aluno, adotando uma linguagem acessível e metodologias diferenciadas, contribuindo, assim, para a apropriação do conhecimento. Esta preocupação que surge no plano 4 sugerido pela professora P3, também é explicitada pela professora P2 que, em suas aulas, busca "[...] adequar os conteúdos e também linguagem científica”.

Uma aula prática, com a proposta de confeccionar um boneco com sementes de alpiste, pode auxiliar na aprendizagem da aluna, já que a mesma gosta de atividades lúdicas. A professora P1 utiliza aulas práticas no ensino de Ciências como forma de interação entre o grupo de colegas, proporcionando a cooperação mútua e o respeito as diferenças e indica que "Procuro aulas mais práticas onde faz que todos possam compartilhar aprendizado e possam em conjunto ajudar os colegas com maiores dificuldades".

O auxílio de um profissional, a tesoura adaptada e a atividade diferenciada de montagem do relatório da aula prática, com frases já prontas, são adaptações que oportunizam a participação da aluna em todos os momentos da aula.

Minetto (2008, p.60) aponta que "os diretores e os coordenadores são peças-chave no processo inclusivo" pois, quando esses entendem a necessidade das adaptações curriculares, podem auxiliar os professores no enfrentamento das dificuldades, na busca de recursos humanos, como os profissionais de apoio e outros materiais que são essenciais para 0 desenvolvimento do trabalho docente.

Os planos adaptados, enviados pelas professoras, evidenciam que as mesmas acreditam que as adaptações curriculares possam favorecer o ensino de Ciências e proporcionar que estudantes com deficiência acompanhem o conteúdo da série/ano em que estão matriculados. Percebe-se que a elaboração de um plano de aula adaptado é uma tarefa que exige conhecimento e dedicação por parte do professor, pois demanda que o docente reveja seus objetivos, sua metodologia, analisando os recursos e materiais a serem empregados, adequando a complexidade e o tempo das atividades.

\section{Considerações finais}

Os resultados da pesquisa inferem que a adaptação curricular é essencial para a inclusão dos estudantes, a fim de acompanhar os conteúdos de Ciências. As contribuições realizadas pelas professoras também indicam que existe uma gama de possibilidades de ensinar Ciências aos estudantes com deficiências intelectual, sensorial e/ou motora, 
http://dx.doi.org/10.5902/1984686X63190

transtornos do espectro autista, bem como estudantes com superdotação/altas habilidades, a partir da utilização das adaptações curriculares. Mas cabe salientar que, para utilizá-las, primeiramente, os professores devem ter conhecimentos sobre as diferentes deficiências na perspectiva da educação inclusiva.

O contexto escolar é um ambiente dinâmico e com demandas diversas, partindo desse pressuposto nenhuma formação inicial dará conta de preparar o professor integralmente para a prática pedagógica. Sabe-se que a formação do professor é um processo contínuo, que se constrói com o trabalho diário ao longo da atuação docente, por isso é importante oferecer aos professores oportunidades de desenvolver subsídios teóricos e metodológicos que ainda Ihes faltam, para lidar com a heterogeneidade presente na escola. Cursos de formação continuada, como por exemplo, o curso aqui relatado, podem ser uma oportunidade de discutir saberes, trocar ideias, refletir e encontrar subsídios para planejar suas aulas com práticas, materiais e recursos que atendam aos estudantes de forma mais específica, auxiliando a prática tanto de quem está no início da caminhada docente, quanto profissionais que exercem à docência a mais tempo e necessitam adequar suas práticas para contemplar a diversidade.

\section{Referências}

ADAMS, F.W. Docência, formação de professores e educação especial nos cursos de Ciências da natureza. 2018. 264 fp. Dissertação (Mestrado Programa de Pós-Graduação em Educação). Universidade Federal de Goiás, Catalão, GO, 2018. Disponível em: http://repositorio.bc.ufg.br/tede/handle/tede/8548. Acesso em: 29 mar. 2019.

BENITE, A. M.C.; BENITE, C.R. M.; VILELA-RIBEIRO, E.B. Educação inclusiva, ensino de Ciências e linguagem científica: possíveis relações. Revista Educação Especial, Santa Maria, v. 28, n. 51, p.83-91, 2015. Disponível em:

https://periodicos.ufsm.br/educacaoespecial/article/view/7687/pdf. Acesso em: 29 mar. 2019.

BERETA, M.S. Adaptação curricular no ensino de ciências: reflexões de professores de escolas, 2019. Dissertação (Mestrado em Ensino de Ciências e Matemática) - Universidade Luterana do Brasil, Canoas-RS, 2019.

BERETA, M.S.; GELLER, M. Adaptação curricular: desafios para professores que ensinam ciência. In: Encontro de Ciências em Educação para Sustentabilidade ECES, n.3, 2018. Canoas-RS: Universidade Luterana do Brasil.

BEZERRA, M.J.S.; OLIVEIRA, G.F. Escola Inclusiva: articulação curricular. Revista Multidisciplinar e de Psicologia, v.10, n.31, p. 237-245, 2016. Disponível em: https://idonline.emnuvens.com.br/id/article/view/564/0. Acesso em: 15 mar. 2019. 
BLANCO, R. A atenção à diversidade na sala de aula e as adaptações do currículo. In: COLL, C.; MARCHESI, A.; PALÁCIOS, J. et al. Desenvolvimento psicológico e educação: transtornos de desenvolvimento e necessidades educativas especiais. Porto Alegre: Artmed, 2004.

BRASIL. Instituto Nacional de Estudos e Pesquisas Educacionais Anísio Teixeira. Censo Escolar, 2018. Disponível em: http://portal.inep.gov.br/informacao-dapublicacao/lasset_publisher/6JYIsGMAMkW1/document/id/6386080. Acesso em: 20 out. 2019.

BRASIL. Lei 9394. Lei de Diretrizes e Bases da Educação: Lei 9394. Brasília: MEC, 2017.

BRASIL. Lei 13.146. Lei Brasileira de Inclusão: Estatuto da Pessoa com Deficiência. Brasília, DF, 2015.

CAPELLINI, V.L.M.F. Adaptações curriculares na inclusão escolar: Contrastes entre dois países. Curitiba/PR: Appris, 2018.

DALONSO, A.L.G. Adequações curriculares: eis-me aqui. Nasci, logo existo. Revista @rquivo Brasileiro de Educação, v. 5, n. 11, p.6-2, 2017. Disponível em:

http://periodicos.pucminas.br/index.php/arquivobrasileiroeducacao/article/view/13319. Acesso em: 29 mar. 2019.

FERNANDES, S.F.P.; ROSA, D.E.G. A formação de professores de Ciências Biológicas e a educação inclusiva: uma interface da formação inicial e continuada. In: IX Encontro

Nacional de Pesquisa em Educação em Ciências. Águas de Lindóia: ABRAPEC, 2013. Disponível em: http://www.nutes.ufrj.br/abrapec/ixenpec/atas/resumos/R1709-1.pdf. Acesso em: 15 mar. 2019.

GARNICA, T.P.B. et al. O saber-fazer na formação de professores para a inclusão escolar: um levantamento bibliográfico. Revista Ensino \& Pesquisa, v.14, n.02, p. 58-87, 2016. Disponível em: http://periodicos.unespar.edu.br/index.php/ensinoepesquisa/article/view/970. Acesso em: 20 mar. 2019.

GUADAGNINI, L.; DUARTE, M. Adaptação curricular para alunos com deficiência intelectual no relato dos professores das escolas estaduais paulistas. Revista Espaço do Currículo, v.8, n.3, p. 437-452, 2015. Disponível em:

https://periodicos.ufpb.br/index.php/rec/article/view/rec.2015.v8n3.437452. Acesso em: 12 mar. 2019.

HOFFMANN, J. Avaliar: respeitar primeiro educar depois. Porto Alegre: Mediação, 2013.

LIPPE, E.M.O.; CAMARGO, E.P. O ensino de Ciências e seus desafios para a inclusão: o papel do professor especialista. In: NARDI, R. (org). Ensino de Ciências e matemática, I: temas sobre a formação de professores. São Paulo: UNESP; São Paulo: Cultura Acadêmica, 2009. Disponível em: http://books.scielo.org/id/g5q2h/pdf/nardi9788579830044-09.pdf. Acesso em: 29 mar. 2019.

LOPES, S. Adaptação curricular: o que é? Por quê? Para quem? E como fazê-la? Educação Básica Revista. vol. 3, n.1, p.3-28, 2017. 
http://dx.doi.org/10.5902/1984686X63190

MINETTO, M.F. Currículo na educação inclusiva: entendendo esse desafio. 2. ed. Curitiba: Ibpex, 2008.

NASCIMENTO, G.M., GELLER, M. Ensino de ciências e políticas públicas de educação inclusiva: um estudo teórico. In: X Encontro Nacional de Pesquisa em Educação em Ciências. Águas de Lindóia: ABRAPEC, 2015. Disponível em: http://www.abrapecnet.org.br/enpec/x-enpec/anais2015/resumos/R1661-1.PDF. Acesso em: 10 mar. 2019.

PIMENTEL, S.C. Formação de professores para a inclusão: saberes necessários e percursos formativos. In: MIRANDA, T.G; FILHO, T.A.G. (org.). O professor e a educação inclusiva formação, práticas e lugares. Salvador: EDUFBA, 2012.

ROSENTHAL, G. Pesquisa social interpretativa: uma introdução. 5. ed. Porto Alegre: EDIPUCRS, 2014.

SILVA, E.N.; SALGADO, A.H.I. O ensino de ciências para alunos com deficiência visual. Estariam os professores capacitados para lidar com esse público? In: IX Encontro Nacional de Pesquisa em Educação em Ciências. Florianópolis/SC: ABRAPEC, 2017. Disponível em: http://www.abrapecnet.org.br/enpec/xi-enpec/anais/resumos/R0260-1.pdf. Acesso em: 5 mar. 2019.

SILVA, M.R. Adequação curricular uma prática educacional inclusiva. 2015. 44 fp. Trabalho de Conclusão de Curso (Especialização) - Universidade de Brasília - UNB. Brasília, 2015. Disponível em: https://bdm.unb.br/bitstream/10483/14550/1/2015_MilenaRosanedaSilva_tcc.pdf. Acesso em: 29 mar. 2019.

SILVA, T.M.F.; MESQUITA, N.A.S. Formação continuada de professores de ciências e o ensino e aprendizagem de conceitos científicos: em foco a adaptação de atividades lúdicas para sala de aula inclusiva. In: IX Encontro Nacional de Pesquisa em Educação em Ciências. Florianópolis/SC: ABRAPEC, 2017. Disponível em: http://www.abrapecnet.org.br/enpec/xi-enpec/anais/resumos/R1529-1.pdf. Acesso em: 5 mar. 2019.

SOUSA, K.C. A formação docente para a educação especial e a prática profissional do professor. 2017. 99 fp. Dissertação (Mestrado em Docência e Gestão da Educação) Universidade Fernando Pessoa Faculdade de Ciências Humanas e Sociais. Porto. Disponível em: https://bdigital.ufp.pt/handle/10284/6041. Acesso em: 29 mar. 2019.

ZABOROSKI, A.P. et al. O ensino colaborativo e a formação permanente dos professores para o desenvolvimento da educação inclusiva. Revista Diálogos e Perspectivas em Educação Especial, v.4, n. 1, p. 119-130, 2017. Disponível em: http://www2.marilia.unesp.br/revistas/index.php/dialogoseperspectivas/article/view/7334. Acesso em: 29 mar. 2019.

\section{(i) (2)}

This work is licensed under a Creative Commons Attribution-NonCommercial 4.0 International (CC BY-NC 4.0) 